OPEN ACCESS

Edited by:

Wen Zhou,

Case Western Reserve University,

United States

Reviewed by:

Jean-Yves Scoazec,

Institut Gustave Roussy, France

Dario Giuffrida,

Mediterranean Institute of Oncology

(IOM), Italy

*Correspondence:

Samira Mercedes Sadowsk

Samira.Sadowski@nih.gov

Specialty section:

This article was submitted to

Cancer Endocrinology,

a section of the journal

Frontiers in Endocrinology

Received: 23 June 2020

Accepted: 30 November 2020

Published: 18 January 2021

Citation:

Chatani PD, Agarwal SK and

Sadowski SM (2021) Molecular

Signatures and Their Clinical Utility in

Pancreatic Neuroendocrine Tumors.

Front. Endocrinol. 11:575620.

doi: 10.3389/fendo.2020.575620

\section{Molecular Signatures and Their Clinical Utility in Pancreatic Neuroendocrine Tumors}

\author{
Praveen Dilip Chatani ${ }^{1}$, Sunita Kishore Agarwal $^{2}$ and Samira Mercedes Sadowski ${ }^{\text {* }}$ \\ 1 Endocrine Surgery Section, Center for Cancer Research, National Cancer Institute, National Institutes of Health, Bethesda, \\ MD, United States, ${ }^{2}$ Metabolic Diseases Branch, National Institute of Diabetes and Digestive and Kidney Diseases, National \\ Institutes of Health, Bethesda, MD, United States
}

Pancreatic neuroendocrine tumors (PNETs) are classified based on their histologic differentiation and proliferative indices, which have been used extensively to determine prognosis. Advances in next-generation sequencing and other high-throughput techniques have allowed researchers to objectively explore tumor specimens and learn about the genetic alterations associated with malignant transformation in PNETs. As a result, targeted, pathway-specific therapies have been emerging for the treatment of unresectable and metastatic disease. As we continue to trial various pharmaceutical products, evidence from studies using multi-omics approaches indicates that clinical aggressiveness stratifies along other genotypic and phenotypic demarcations, as well. In this review, we explore the clinically relevant and potentially targetable molecular signatures of PNETs, their associated trials, and the overall differences in reported prognoses and responses to existing therapies.

Keywords: molecular signatures, signaling pathway, tumorigenesis, clinical trial, neuroendocrine carcinoma, pancreatic neuroendocrine tumor

\section{INTRODUCTION}

Neuroendocrine tumors (NETs) are a subset of neoplasms arising from neuroendocrine cells throughout the body that are characterized by their ability to produce peptides causing distinctive hormonal syndromes. Pancreatic neuroendocrine tumors (PNETs) comprise $1 \%$ to $3 \%$ of all newly diagnosed pancreatic cancers with an annual incidence of approximately 3.6 per 100,000 persons $(1,2)$. Though they represent only $7 \%$ of all gastrointestinal NETs, they are significantly more likely to present with distant metastases, at a higher grade, or with unresectable disease $(\sim 65 \%)$ compared to their stage-matched lung and small bowel counterparts $(3,4)$.

The prognosis of NETs is highly dependent on their histologic presentation. Median survival ranges from as low as 24 months in advanced, unresectable disease to seven years in early stage, resectable disease (5). In 2017, the World Health Organization established a new classification system utilizing grade (G1-G3, based on mitotic figures and Ki-67 index) and histologic differentiation (well-differentiated "neuroendocrine tumors" vs. poorly differentiated "neuroendocrine carcinomas") (Table 1) (6). This system aims to stratify tumors by aggressiveness, scale treatment accordingly, and guide discussions regarding prognosis. The update was prompted by significant disparities in patient survival when classified by grade alone. 
TABLE 1 | World Health Organization classification and grading of pancreatic neuroendocrine neoplasms (2017) (6).

\begin{tabular}{lcc}
\hline $\begin{array}{l}\text { Differentiation and } \\
\text { Grade }\end{array}$ & $\begin{array}{c}\text { Proliferation Index Ki-67 } \\
\text { (\%) }\end{array}$ & $\begin{array}{c}\text { Mitotic Index } \\
\text { (Mitoses } \\
\text { per 10 HPFs) }\end{array}$ \\
\hline Well-Differentiated & $<3$ & \\
- G1 PNET & $3-20$ & $<2$ \\
- G2 PNET & $>20$ & $2-20$ \\
- G3 PNET & & $>20$ \\
Poorly Differentiated & $>20$ & $>20$ \\
- G3 PNEC & & \\
\hline
\end{tabular}

PNET, Pancreatic Neuroendocrine Tumor.

PNEC, Pancreatic Neuroendocrine Carcinoma.

HPFs, High power fields.

While G3 tumors comprise only $~ 10 \%$ of PNETs, they occupy a spectrum of aggressiveness depending largely on their histologic differentiation (7-10).

Although functionality is not considered in the classification, the vast majority of PNETs (85\%) are clinically non-functional and are often incidentally discovered during abdominal imaging ( 40\%) (11, 12). The clinical presentation of non-functional PNETs is due to mass-related burden of the primary tumor or metastatic deposits (up to $50 \%$ have metastatic disease upon presentation) (13). For this reason, they are often diagnosed at more advanced stages and are associated with poorer prognosis. Their median overall survival (OS) is 26 months versus 54 months in their functional counterparts (14-16).

PNETs are most commonly sporadic, but they may also occur as part of five hereditary syndromes: multiple endocrine neoplasia type 1 (MEN1), MEN4, von Hippel-Lindau (VHL), neurofibromatosis type 1 (NF1), and tuberous sclerosis complex (TSC). Together, these syndromes account for less than $10 \%$ of PNETs and, while they are more likely to present with multifocal disease, their rate of metastasis is slightly lower at $23 \%$ to $33 \%$ of cases $(16,17)$. Among the hereditary syndromes, functioning PNETs such as insulinomas, gastrinomas, glucagonomas, VIPomas, and somatostatinomas are observed most frequently in MEN1 $(18,19)$.

Amidst this wide array of severities, surgery remains the cornerstone of treatment for this disease and should be pursued for all local or metastatic neoplasms amenable to complete resection (20-22). Presently available systemic options are limited to long-acting release octreotide, the mTOR inhibitor everolimus, and the VEGF inhibitor sunitinib (23-25). These drugs offer a modest improvement in progression-free survival but have not been shown to impact OS. Despite the relative success of surgery, up to $50 \%$ of patients who undergo complete resection will develop metachronous liver metastases and, although recurrence-free survival is positively associated with well-differentiated tumors, it is evident that the current characterization model does not successfully separate biologically favorable tumors from those with a predilection for recurrence/metastasis (12).

Advances in next-generation sequencing have allowed researchers to objectively explore tumor specimens and learn about the genetic alterations that drive malignant transformation in PNETs. Analyses of this molecular landscape have identified significant heterogeneity in the mutational profiles of nonfunctional PNETs. However, four core pathways have been implicated: DNA damage/repair, chromatin remodeling, alternative lengthening of telomeres, and PI3K/AKT/mTOR signaling (26). Among the functional tumors, genetic and expression profiling of insulinomas did not show mutations in MEN1, DAXX/ATRX, and mTOR pathway genes that are frequently mutated in non-functional PNETs (27). Approximately 3\% to $30 \%$ of insulinomas show a recurrent mutation in YY1 (p.T372R), a gene encoding a transcription factor (28-30). Also associated with insulinomas are rare mutations or gene expression changes of a few epigenetic modifier genes (H3F3A, KDM6A, ATR, and EZH2) (27). The molecular patterns of presentation that have been identified in PNETs can help us predict clinical outcomes.

This review will explore the clinically relevant and potentially targetable mutational and immunohistochemical features, henceforth referred to as "molecular signatures", of nonfunctional PNETs, their associated trials, and overall differences in reported prognoses.

\section{MOLECULAR MECHANISMS AND PROGNOSIS IN PNETS}

Inherited tumor syndromes, including MEN1, VHL, NF1, and TSC, represent a minority of PNETs, but uncovering their molecular mechanisms has furthered our understanding of their sporadic counterparts. Somatic mutations or alterations of the relevant syndromic genes are frequently seen in sporadic PNETs. Up to $44 \%$ of non-familial PNETs harbor a somatic MEN1 alteration, while $25 \%$ have non-mutational VHL inactivation, and downregulation or mutation of the TSC2 gene is seen in $35 \%$ and $9 \%$, respectively (26). This supports the notion of shared pathways of tumorigenesis in familial and non-familial tumors centered around the MEN1 gene (Figure 1). Further complicating matters, germline mutations in genes linked to familial syndromes (i.e., MEN1, VHL) have also been detected in patients with apparently sporadic PNETs (35). In this section, we explore the complex molecular landscape of PNETs as it relates to prognosis.

\section{MEN1}

Menin, the gene product of $M E N 1$, is a predominantly nuclear protein that functions as a tumor suppressor by i) interacting with various transcription factors and histone modification enzymes to regulate gene transcription, ii) regulating cell cycle progression (via upregulation of CDKN2C/ CDKN1B expression), and iii) participating in specific cell signaling processes (for example, menin alters AKT1 subcellular localization to regulate the PI3K/AKT/mTOR signaling pathway) (26). Patients with MEN1 (a heterozygous germline mutation in the MEN1 gene inherited in an autosomal-dominant fashion) have a $40 \%-80 \%$ chance of developing a PNET during their lifetime, making it the second-most-frequently expressed 


\section{Genotypes}

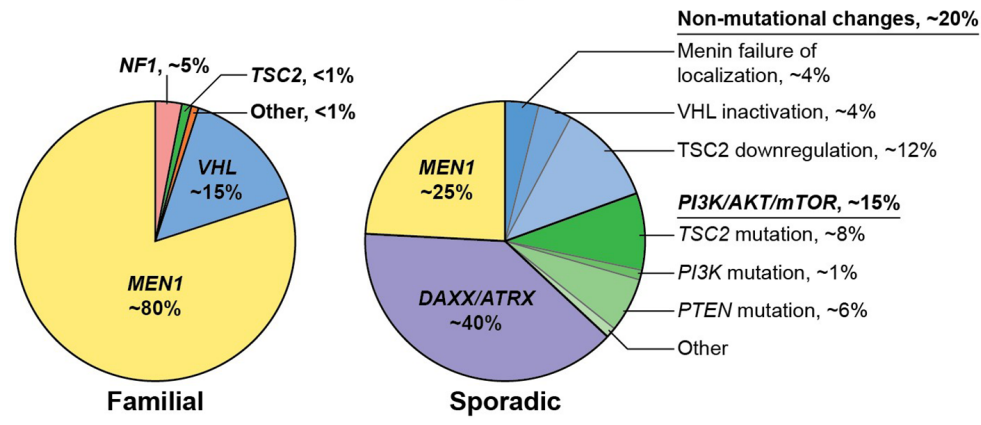

B

Phenotypes

\begin{tabular}{|c|c|}
\hline Positive prognostic factors & Poor prognostic factors \\
\hline $\begin{array}{l}\text { - VEGF expression and hypervascularity } \\
\text { - Associated with well-differentiated } \\
\text { tumors and good prognosis } \\
\text { - SSTR-2 expression } \\
\text { - Associated with longer overall and } \\
\text { progression-free survival } \\
\text { - Loss of Rb expression } \\
\text { - Associated with more } \\
\text { chemo-responsive PNECs }\end{array}$ & $\begin{array}{l}\text { - Alternative lengthening of telomeres } \\
\text { - Aggressive behavior } \\
\text { - Poor survival } \\
\text { - ARX+/PDX1- tumors } \\
\text { - Increased risk of metastasis and } \\
\text { - disease recurrence } \\
\text { - } 100 \% \text { found to have ALT } \\
\text { - Overexpression of miR-196a } \\
\text { - Shorter disease-free survival } \\
\text { - Aggressive histologic features } \\
\text { - Loss of p16 staining } \\
\text { - Associated with more aggressive PNECs }\end{array}$ \\
\hline
\end{tabular}

FIGURE 1 | (A) Reported distribution of genotypic alterations in familial and sporadic pancreatic neuroendocrine tumors (PNETs). (B) Prognostic associations of various non-functional PNET phenotypes. (11, 14, 31-34).

clinical manifestation of the syndrome next to parathyroid neoplasms (36). These are most commonly non-functional PNETs with a tendency towards multiplicity. Tumor size at the time of presentation is also an important prognostic factor, as lesions $>2 \mathrm{~cm}$ harbor a higher risk of malignancy $(17,37)$. Tumors show loss of heterozygosity at the MEN1 locus on chromosome 11q13 and abnormally low nuclear staining of menin $(38,39)$. While this is the established mutational mechanism in familial cases, a 2010 combined genetic and immunohistochemical study of MEN1 mutations and menin expression demonstrated that up to $80 \%$ of sporadic cases had strong cytosolic staining of the protein, suggesting a failure of nuclear localization, while just $25 \%$ of the patients harbored a mutation in the gene itself (31). This suggests that other pathways or genes are involved in the altered expression of menin or its downstream effects. Directly or indirectly, MEN1 and its associated pathways play an important role in the neoplastic process of PNETs and represent potential therapeutic targets. Among sporadic PNETs, $44 \%$ of non-functional tumors show MEN1 mutations, and the prevalence of a MEN1 mutation in functional tumors is as follows: glucagonoma (60\%), VIPoma (57\%), gastrinoma (38\%), and insulinoma (2\%-19\%) (40).

\section{VHL}

Contrary to MEN1, VHL-associated PNETs are reported in just $10 \%-17 \%$ of syndromic patients, most of which present at a young age and with non-functional, multi-focal disease throughout the pancreas $(32,41-44)$. Although $V H L$ mutations are rarely seen in sporadic PNETs, non-mutational VHL inactivation is seen in up to a quarter of sporadic PNETs. Compared with sporadic tumors, though, resected VHL-associated PNETs have better long-term outcomes (45). VHL-driven PNETs likely represent a distinct subset of these tumors. Unlike their MEN1 or DAXX/ATRX mutation-positive counterparts, genetic alterations in $V H L$ mutation driven PNETs are predominantly related to angiogenesis and hypoxia-inducible factor (HIF) signaling (46). The VHL protein itself serves as a regulator of HIF-1 $\alpha$. Thus, inactivation of $V H L$ induces angiogenesis and abnormal cell metabolism. A quantitative RT-PCR study of 52 genes in 18 patients with VHL-associated PNETs demonstrated a unique pattern of gene upregulation related to HIF signaling, angiogenesis, and specific growth factor/cell cycle component expression when compared to sporadic tumors (46).

\section{HIF-1 $\alpha$ and VEGF}

Whether sporadic or familial, PNETs are highly vascularized owing to increased levels of proangiogenic factors such as HIF$1 \alpha$ and vascular endothelial growth factor (VEGF). The HIF-1 pathways regulate over 100 genes involved in angiogenesis including VEGF, PDGF, and angiopoietin (ANG-1 and ANG-2) (47). VEGF itself is expressed in $\sim 80 \%$ of PNETs. Welldifferentiated PNETs have been shown to express higher levels of these factors and have a higher density of microvasculature than poorly differentiated PNETs $(48,49)$. Surprisingly, this 
higher microvessel density has been associated with a better prognosis (50). Immunostaining of tumor sections from 45 patients with PNETs showed that well-differentiated tumors had high cytoplasmic expression of VEGF and HIF-1 $\alpha$, whereas poorly differentiated carcinomas were associated with nuclear HIF-1 $\alpha$ expression. Also, nuclear HIF- $1 \alpha$ expression was associated with the presence of necrosis, larger tumor size, low microvascular density, and shorter survival (49). Insights into the mechanisms underlying angiogenesis have led to the development of VEGF inhibitors such as bevacizumab and sunitinib that are being tested as potential PNET therapies (51, 52). Recently, a Phase Ib/II trial of surufatinib, a selective VEGF receptor (VEGFR) small molecule tyrosine kinase inhibitor, demonstrated encouraging antitumor activity with minimal toxicities in patients with advanced NETs (53).

\section{DAXXIATRX}

Up to $43 \%$ of sporadic PNETs have a mutation in genes encoding for a chromatin remodeling/stabilization complex composed of death domain-associated (DAXX) protein and $\alpha$-thalassemia/ intellectual disability syndrome X-linked (ATRX) protein (33). This heterodimer is implicated in remodeling at the telomeric and pericentromeric regions, and incorporating the histone variant H3.3, a mechanism supported by nuclear staining of the proteins in DAXX/ATRX wild-type PNETs that is absent in PNETs with mutant proteins $(14,54-56)$. Mutations in DAXX/ $A T R X$ are mutually exclusive, can promote tumorigenesis, and correlate with alternative lengthening of telomeres (ALT), a telomerase-independent mechanism of telomere lengthening (11). This phenotypic abnormality was found in $61 \%$ of patients in a molecular analysis of PNETs by Heaphy et al. The study demonstrated a significant correlation between either $A T R X / D A X X$ mutations or the loss of their respective nuclear proteins and the presence of ALT across multiple tumor histologies (33). Though this genotype-phenotype relationship is strong, it is present in only $\sim 3 \%$ of all human neoplasms. Regardless, it represents a clinically significant marker, as research predicts that ALT indicates resistance to antitelomerase therapies and may harbor prognostic value (57).

Despite being exclusively linked to well-differentiated PNETs, ATRX/DAXX-mutated PNETs have been clinically associated with aggressive behavior and poor survival (58). A large retrospective study attributed this poor survival to increased chromosomal instability seen in patients with DAXX/ATRXmutated PNETs (59). Clinicopathologic and genetic analysis of 76 patients with well-differentiated PNETs in South Korea showed DAXX/ATRX loss to be independently associated with poor prognosis alongside metastatic disease on presentation (60). Telomere-specific fluorescence in situ hybridization (FISH) analysis of 109 well-differentiated PNETs only identified $D A X X / A R T X$ mutations and ALT phenotype in patients with tumors greater than $3 \mathrm{~cm}$ and lymph node metastases, suggesting that these changes may be specific to the later stages of disease (61). Similarly, in multiple independently examined cohorts of surgically resected PNETs, ALT-positive tumors displayed a significantly higher grade, size, and pT staging. ALT phenotype and loss of DAXX/ARTX staining correlated strongly $(P<0.05)$ with lymphovascular invasion, perineural invasion, lymph node involvement, distant metastasis, and shorter recurrence-free survival $(62,63)$.

\section{PI3K/AKT/mTOR}

Expression profiles of sporadic PNETs have shown a correlation between prognosis and the $\mathrm{PI} 3 \mathrm{~K} / \mathrm{AKT} / \mathrm{mTOR}$ pathway that is involved in the regulation of cellular proliferation, growth, survival, and other vital functions (64). Exome sequencing of PNETs has shown that $\sim 15 \%$ of well-differentiated tumors harbor somatic mutations in the PI3K/AKT/mTOR pathway genes, including $7 \%$ in PTEN, $9 \%$ in TSC2, and $1 \%$ in PIK3CA (14). Whole-genome sequencing of 102 sporadic PNETs found PTEN and TSC1/2 mutations to be mutually exclusive (35). As it is central to multiple tumorigenic pathways, downregulation of mTOR pathway inhibitors such as PTEN and TSC2 was a highly significant finding $(\sim 85 \%)$ in a gene expression profiling of PNETs, even in the absence of a pathway-specific mutation. Under-expression of these essential regulatory factors was associated with more-advanced stage, increased risk of metastasis, and shortened disease-free survival and overall survival $(11,64)$.

\section{Chromosomal Aberrations}

Mutations alone provide the rationale for tumorigenesis in only about $40 \%$ of sporadic PNETs, with the remaining cases ascribed to chromosomal/epigenetic alterations (26). Various studies have identified non-mutational biomarkers associated with tumor progression/metastasis that could potentially assist with management. Copy-number alterations at certain chromosomal loci, such as 6p22.2-p22.1, 8q24.3, 9q34.11, and $17 \mathrm{p} 13.1$ have been associated with poorer prognosis (65). This is an important area of ongoing research, though the prognostic implications of other copy-number alterations and chromosomal translocations are poorly defined at this time.

\section{Micro-RNAs and DNA Methylation}

miRNAs are short, non-coding RNA molecules regulating gene expression at the post-transcriptional level; they have been shown to regulate up to $60 \%$ of all coding genes and have been implicated in a wide range of biologic processes, including carcinogenesis (66). A micro-array study of 44 pancreatic primary tumors, including functional and non-functional PNETs, discovered patterns of miRNA expression that could distinguish any tumor type from normal pancreas (67). For example, expression of $m i R-103$ and $m i R-107$ in the absence of $m i R-155$ distinguished tumors from normal pancreas. miRNA expression patterns were able to distinguish PNETs from acinar carcinomas and further segregate PNETs by functionality, Ki-67 index, and presence of liver metastases. More recently, a comparison of miRNA and mRNA transcriptomes in PNET samples showed an association between miRNA profiles and commonly described genetic alterations, such as DAXX/ATRX and MEN1 (68). Over-expression of $m i R-196 a$ in post-resection PNETs has been associated with poor prognosis, shorter diseasefree survival, and more aggressive histologic profile (stage, mitotic rate, Ki-67) (69). There is mounting evidence that 
miRNA expression profiles may serve as a clinically useful biomarker for diagnostic, prognostic, and therapeutic purposes (70).

DNA methylation profiles of PNETs may also serve as relevant biomarkers for tumor stratification. Hypermethylation or hypo-methylation at $\mathrm{CpG}$ islands (GC-rich DNA regions), often located in the promoter regions of genes, is associated with gene silencing or gene activation, respectively. Higher global DNA hypermethylation was detected in nonfunctional PNETs from MEN1 patients in comparison with sporadic and VHL-associated PNETs (71). Also, promoter hypermethylation was observed as a frequent event in MEN1associated advanced PNETs (72). Validation of these findings in independent cohorts of familial and sporadic PNETs will help to determine the importance of DNA methylation as a biomarker.

\section{Circulating Tumor DNA/RNA}

Minimally invasive liquid biopsy tests for advanced cancers using blood/plasma have been shown to detect tumor-specific mutations in circulating cell-free tumor DNA (ctDNA), and recent data from studies of the NETest have shown successful detection of tumor-specific transcripts in circulating RNA (73, 74). Genç et al. demonstrated that this multigene blood test could effectively detect PNET recurrence after surgical resection (test performed after recurrence) in a cohort of non-functional (83\%) and functional (17\%) PNETs (75). A recent meta-analysis shows an accuracy of $90.2 \%-93.6 \%$ as a marker of natural history of NET (76). However, large validation studies with long-term follow-up are needed. The NETest could help in the detection of sporadic PNETs or their response to therapy; however, the utility of the NETest to detect PNETs or their metastases in patients presenting with familial syndromes could be confounded by the simultaneous presence of other tumors.

\section{Cell of Origin and Transcription Factors}

The clinical behavior of non-functional PNETs is also correlated with the transcriptomic profiles of specific islet cell types, namely $\alpha$ - and $\beta$-cells that undergo differentiation via transcription factors ARX and PDX1, respectively. A study of 142 nonfunctional PNETs (MEN1-associated and sporadic) showed that $84 \%$ of tumors expressed either ARX or PDX1, predominantly, and could be classed as "A-type" (resembling $\alpha$-cells) or "B-type" (resembling $\beta$-cells) (34). Of the 103 tumors with subsequent distant relapses, almost all were $\mathrm{ARX}^{+} \mathrm{PDX}{ }^{-}$ and had ALT. The authors postulated that this molecular stratification could provide insight into the correlation of cell lineage with disease course and inform postoperative clinical decisions.

\section{Unique Molecular Mechanisms in Pancreatic Neuroendocrine Carcinomas}

To this point, this review has focused on molecular alterations more common in well-differentiated pancreatic neuroendocrine tumors. It should be noted that poorly differentiated pancreatic neuroendocrine carcinomas (PNECs), which carry significantly worse prognoses, represent a genetically distinct biology by comparison. PNECs often harbor alterations in $R b$ and TP53
( $\sim 74 \%$ and $95 \%$, respectively). An immunostaining study showed that inactivation of these two pathways is a central feature of PNEC development (58). Aberrant p16 staining was found to be mutually exclusive to $\mathrm{Rb}$ anomalies, such that all PNECs had some disruption of the p16/Rb pathway. BCL2 overexpression, while seen in both PNEC (74\%) and PNET (18\%) samples, was much more common in the former. In contrast, SMAD4/DPC4, DAXX, and ATRX staining was found to be intact in all samples (58). Though overall prognosis across all PNECs is dismal, subtle differences in molecular signatures have demonstrated overall differences in prognosis. A study assessing response to platinum-based chemotherapy showed that tumors with loss of $\mathrm{Rb}$ expression had a significantly better response to treatment ( $80 \%$ vs $38.4 \%$ ) than those that retained $\mathrm{Rb}$; a similar improvement in overall response was seen in patients with KRAS mutations compared to those with KRAS wild-type tumors (77\% vs. 23\%) (77). Such distinct molecular signatures aid in characterizing G3 tumors as PNETs or PNECs, thereby delivering potentially accurate prognostic information and, more importantly, tailored therapeutic regimens to patients. As discussed below, recommended treatments by the European Neuroendocrine Tumor Society and the National Comprehensive Cancer Network differ for G3 PNECs $(78,79)$.

\section{THERAPEUTIC ADVANCES AND IMPLICATIONS OF MOLECULAR SIGNATURES IN PNET/PNEC}

In patients with resectable disease, $\mathrm{R} 0 / \mathrm{R} 1$ resection remains the treatment of choice. Unfortunately, the majority of patients with PNETs either present with or develop metastatic disease within two years of surgery, prompting the need for effective systemic therapies (80). So far, there are a number of standard-of-care therapies available, including somatostatin analogues, cytotoxic chemotherapies, inhibitors of the angiogenesis and mTOR pathways, and combinations of multi-drug regimens (Table 2). There are, in addition to established treatment regimens, a number of drugs in clinical trials. However, there is a paucity of data focused on directing these therapies to their most appropriate candidates.

\section{Somatostatin Receptor Expression and Blockade}

Neuroendocrine tumors typically express somatostatin receptors on their cell membranes, which have demonstrated diagnostic, prognostic, and therapeutic utility. Recently, 68-GalliumDOTATATE positron emission tomography demonstrated diagnostic superiority to conventional functional imaging modalities while more accurately identifying clinically aggressive and treatment-refractory tumors $(85,86)$. Of the five different somatostatin receptor (SSTR) subtypes, SSTR-2 is expressed on approximately $80 \%$ of PNETs, making it an attractive target for therapeutic intervention (87). While the ability to mitigate the effects of hormonal over-secretion is, in 
TABLE 2 | Available therapeutic agents and their respective targets.

\begin{tabular}{|c|c|c|c|c|c|}
\hline Molecular Pathway & Target & Available Therapeutic & FDA Approval & Outcomes (vs. placebo/control) & Source \\
\hline \multirow[t]{3}{*}{ Angiogenesis } & VEGF & $\begin{array}{l}\text { Bevacizumab } \\
\text { Pazopanib }\end{array}$ & & & \\
\hline & + PDGF & Sunitinib & * & $\begin{array}{c}\text { ORR: } 9 \% \\
\text { Median PFS: } 12.6 \mathrm{mo} \text { (vs. 5.8) }\end{array}$ & {$[81,82]$} \\
\hline & +cMet & $\begin{array}{l}\text { Sorafenib } \\
\text { Surufatinib }\end{array}$ & * & $\begin{array}{c}\text { ORR: } 19 \% \\
\text { Median PFS: } 21.2 \mathrm{mo}\end{array}$ & [53] \\
\hline \multirow[t]{4}{*}{ Somatostatin } & SSTR-2 & Octreotide & * & $\begin{array}{l}\text { Median OS: } 77.4 \mathrm{mo} \text { (vs. } 73.7 \mathrm{mo}) \\
\text { Median PFS: } 14.3 \mathrm{mo} \text { (vs. } 6 \mathrm{mo})\end{array}$ & [24] \\
\hline & & Lanreotide & * & $\begin{array}{l}\text { Median PFS: NR (vs. 18mo) } \\
\text { PFS at } 24 \mathrm{mo}: 65 \% \text { (vs 33\%) }\end{array}$ & {$[25]$} \\
\hline & & $\begin{array}{c}\text { PRRT } \\
\left({ }^{177} \text { Lu-Dotatate }\right)\end{array}$ & * & $\begin{array}{c}\text { ORR: } 18 \% \text { (vs. 3\%) } \\
\text { PFS at 20mo: } 65 \% \text { (vs. 11\%) }\end{array}$ & [83] \\
\hline & +SSTR-1, 3 and 5 & Pasireotide & & & \\
\hline PIЗK/AKT/mTOR & mTOR & $\begin{array}{l}\text { Everolimus } \\
\text { Temsirolimus }\end{array}$ & * & Median OS: 44mo (vs. 37.7mo) & {$[84]$} \\
\hline Immunomodulation & PD-1 & Pembrolizumab & ** & Not Done & \\
\hline
\end{tabular}

ORR, Overall response rate.

PFS, Progression-free survival.

OS, Overall survival.

${ }^{*}$ Approved for NETS

${ }^{* *}$ Approved for other solid tumors.

and of itself, useful, objective tumor shrinkage with somatostatin analogues is rare, and these drugs have predominantly been used to slow the pace of disease. The phase III CLARINET trial, which compared lanreotide to placebo in 204 patients with nonfunctioning, SSTR-expressing gastrointestinal NETs (45\% of which were pancreatic), showed a significantly prolonged progression-free survival (PFS) with SSTR blockade (25). Based on this data, lanreotide has been approved by the U.S. Food and Drug Administration (FDA) for the treatment of patients with unresectable, well- or moderately differentiated, locally advanced or metastatic gastroenteropancreatic NETs. A study examining the use of lanreotide in NETs postulated that PNETs may fall among the histologies least likely to respond, though there are no studies that stratify the responses by molecular characteristics (88). More recently, the $\beta$-radiation-emitting compound ${ }^{177} \mathrm{Lu}$ Dotatate, a radiolabeled somatostatin analog, was approved for systemic treatment of inoperable or metastatic disease after demonstrating improved PFS and a significantly higher response rate compared to high-dose octreotide LAR (83).

\section{Angiogenic Factor Expression and Inhibition}

A deeper understanding of the molecular features of PNETs, such as their abundant intra-tumoral vasculature and expression of angiogenic factors, has led to the application of targeted therapies like anti-VEGF and anti-PDGF drugs (89). Sunitinib, a potent antagonist of VEGF and PDGF signaling, demonstrated an overall response rate of $9 \%$, with median PFS of 12.6 months versus 5.8 months in placebo-controlled patients, leading to its FDA approval for unresectable, locally advanced or metastatic PNETs $(81,82)$. Other VEGF inhibitors such as bevacizumab have shown similar overall response rates to monotherapy but have demonstrated greater utility as a component of a multi-drug regimen (52). Inhibition of VEGF signaling was, in some pre- clinical models, associated with increased invasiveness and metastasis attributed to the over-expression of c-Met. Subsequent trials examining blockade of this increased c-Met signaling alongside VEGF inhibition identified it as a potential escape mechanism for patients on anti-angiogenic therapies (90). Overexpression of c-MET alone has also been detected in PNETs, making it a therapeutic target in need of further study (91). Drugs such as surufatinib-a small-molecule tyrosine kinase inhibitor of VEGF, fibroblast growth factor, and CSF receptors-aim to target multiple angiogenic pathways simultaneously; encouraging phase Ib/II data for surufatinib has prompted ongoing phase III studies (53). Though a number of studies have examined baseline levels and treatment-related changes in soluble plasma and tumor tissue markers such as VEGF and its associated receptors, none have identified a clinically reliable treatment (92).

\section{mTOR Pathway Dysregulation and Inhibition}

A landmark phase III trial called RADIANT-3 showed a 6.4month improvement in median PFS with an mTOR inhibitor called everolimus but was unable to demonstrate an OS advantage $(23,84)$. A prognostic effect has been observed with lower baseline levels of and treatment-related reduction in chromogranin A, neuron-specific enolase, placental growth factor, and soluble vascular endothelial growth factor receptor $1(84,93,94)$. Several studies have demonstrated mechanisms of resistance responsible for the underwhelming effect of the drug and, although combining mTOR inhibitors with other PI3K/AKT inhibitors and/or anti-angiogenic drugs has proven superior to monotherapy, an organized effort to identify molecular subgroups with more promising responses has yet to be undertaken (52, 95-98). Previous studies have shown that the presence of certain $P I 3 K$ and KRAS mutations may influence breast cancer 
cells' response to everolimus. Meanwhile, deletion of the KRAS mutation restores sensitivity to the therapy (99). Studies examining molecular predictors of response to mTOR inhibition also demonstrated increased efficacy in tumors with a higher percentage of phosphorylated (i.e., activated) mTOR, as assessed by immunohistochemistry $(100,101)$. So far, confirmation of a $\mathrm{PI} 3 \mathrm{~K} / \mathrm{AKT} / \mathrm{mTOR}$ pathway genetic mutation has not precluded inclusion in any trial of mTOR pathway inhibitors in PNETs.

\section{Checkpoint Receptor Expression and Blockade}

Finally, no discussion of contemporary systemic cancer therapies is complete without mentioning immune checkpoint inhibitors. Although PD-1 and PD-L1 expression in PNETs is rare, PD-L2 and abundant $\mathrm{T}$-cell infiltrates have been noted when characterizing the immune microenvironment, suggesting a potential role for checkpoint blockade (102). No association has been seen, however, between $\mathrm{T}$-cell infiltration and aforementioned molecular/mutational signatures in PNET, and further studies are warranted to determine the existence of such links. Initial data from the KEYNOTE-028 study (NCT02054806) showed a 3.7\% response rate, with only one responder being a patient with PNET (103).

\section{Cytotoxic Chemotherapies and Combination Approaches}

Various studies have demonstrated that PNETs are responsive to cytotoxic chemotherapy. Streptozocin, an alkylating agent, was approved by the FDA in the early 1980s for the treatment of neuroendocrine carcinomas, when it achieved a $69 \%$ radiologic response rate and median survival of 2.2 years when administered in conjunction with doxorubicin (104). Concerns surrounding inconsistencies in the reproducibility of these data, toxicity, and the drug's cumbersome infusion schedule have made streptozocin a less-popular agent in the treatment of PNETs (105). Subsequent studies led to increased use of similar alkylating agents like dacarbazine and, more recently, temozolomide, which has produced response rates up to $70 \%$ when delivered in conjunction with capecitabine (106). More recent prospective trials of temozolomide alongside targeted agents such as bevacizumab and everolimus have produced response rates of $33 \%$ and $40 \%$, respectively $(107,108)$. Objective response rates of temozolomide-based therapy in PNEC are similarly unsatisfying at 33\% (109). Patients who lack a certain DNA repair enzyme conferring resistance to temozolomide $\left(\mathrm{O}^{6}\right.$-methylguanine DNA methyltransferase or 'MGMT'), or who have reduced expression of MGMT due to promoter methylation, see greater efficacy of the drug than those with increased expression $(110,111)$; aside from this, there are no studies examining molecular factors predictive of response to cytotoxic chemotherapy $(26,112)$.

The majority of clinical studies with respect to PNET therapies examine small cohorts of patients from single institutions with a lack of consideration given to molecular signature or lack of syndromic patients. Trials of everolimus do not segregate patients based on genetic integrity of their mTOR pathway components, and those examining anti- angiogenic medications are not stratified based on upregulation of anti-angiogenic factors themselves. Moving forward, it is important that these molecular signatures be taken into greater consideration when evaluating the impact of therapeutic approaches. As is often suggested, this will require further multi-institutional collaboration bridged by common nomenclature and classification systems.

\section{PRECISION ONCOLOGY AND THE ROLE OF MOLECULAR SIGNATURE}

A few recent studies have used a precision oncology approach to select drugs and druggable targets in gastroenteropancreatic (GEP) NETs. RNA-seq-derived gene expression patterns in matched primary PNETs and their metastases from 43 patients were analyzed to identify metastasis-associated pathways (113). Metastasis-specific alterations were identified in MAPK, cyclindependent kinase (CDK), topoisomerase (TOP2A), NF-kB, and $\mathrm{PI} 3 \mathrm{~K} / \mathrm{mTOR}$ signaling pathways. This study provides valuable insights into potentially druggable targets for the pre-clinical assessment of pathway-specific drugs to treat advanced PNETs. Another study used RNA-seq analysis of 212 GEP-NET samples (including 83 PNETs) followed by virtual inference of protein activity to identify master regulators that represented highly enriched tumor-essential genes (114). A similar analysis in GEPNET cell lines was coupled with systematic drug perturbation assays using 107 small molecule compounds that could invert specific master regulator protein activity signatures (tumor checkpoint collapse) (114). Entinostat, an HDAC class I inhibitor, demonstrated cytotoxicity and reversal of master regulatory protein activity signatures in DEP-NET cell line models and predicted efficacy in $42 \%$ of tumor specimens (with similar master regulator protein activity signatures). This study shows how to prioritize drugs for preclinical assessment that target specific tumor checkpoints. The choice of cell line models is critical for the success of these precision oncology approaches. Whole-exome sequencing, copy-number analysis, and immunophenotyping of NET cell lines has allowed for a deeper understanding of NET cell line model systems and facilitated in vitro testing of various therapeutics on different NET phenotypes $(113,115)$.

\section{CONCLUSIONS}

Despite significant progress in the characterization of PNETs at the histologic and molecular level, clinically correlative findings have largely been limited to prognostication. This is largely due to the fact that clinical trials are not subject to mutation-specific inclusion criteria. For years, these tumors have been classified by their histologic differentiation and Ki-67 proliferative index. However, it is clear that clinical aggressiveness also stratifies along other genotypic/phenotypic lines. Therefore, future studies must consider important tumor-specific genetic, epigenetic, and transcriptomic alterations before and after therapy, such as MEN1/DAXX/ATRX mutations, ARX expression, and their corresponding phenotypic manifestations (i.e., ALT), as defining 
characteristics that may impact tumor recurrence and the survival of patients with PNETs. As we move into an era of personalized medicine, where next-generation sequencing is more readily and widely available, prior 'one-size fits all' models of classification must be replaced by more-informed systems.

\section{AUTHOR CONTRIBUTIONS}

PC and SS: Conception of the work and drafted the article. SS and SA: Critical revision of the article. All authors contributed to the article and approved the submitted version.

\section{REFERENCES}

1. Batukbhai BDO, De Jesus-Acosta A. The Molecular and Clinical Landscape of Pancreatic Neuroendocrine Tumors. Pancreas (2019) 48:9-21. doi: 10.1097/MPA.0000000000001189

2. Dasari A, Shen C, Halperin D, Zhao B, Zhou S, Xu Y, et al. Trends in the Incidence, Prevalence, and Survival Outcomes in Patients With Neuroendocrine Tumors in the United States. JAMA Oncol (2017) 3:1335-42. doi: 10.1001/jamaoncol.2017.0589

3. Yao JC, Hassan M, Phan A, Dagohoy C, Leary C, Mares JE, et al. One hundred years after "carcinoid": epidemiology of and prognostic factors for neuroendocrine tumors in 35,825 cases in the United States. J Clin Oncol (2008) 26:3063-72. doi: 10.1200/JCO.2007.15.4377

4. Lawrence B, Gustafsson BI, Chan A, Svejda B, Kidd M, Modlin IM. The epidemiology of gastroenteropancreatic neuroendocrine tumors. Endocrinol Metab Clin North Am (2011) 40:1-18, vii. doi: 10.1016/j.ecl.2010.12.005

5. Djukom C, Porro LJ, Mrazek A, Townsend CM Jr., Hellmich MR, Chao C. Dual inhibition of PI3K and mTOR signaling pathways decreases human pancreatic neuroendocrine tumor metastatic progression. Pancreas (2014) 43:88-92. doi: 10.1097/MPA.0b013e3182a44ab4

6. Nagtegaal ID, Odze RD, Klimstra D, Paradis V, Rugge M, Schirmacher P, et al. The 2019 WHO classification of tumours of the digestive system. Histopathology (2020) 76:182-8. doi: 10.1111/his.13975

7. Velayoudom-Cephise FL, Duvillard P, Foucan L, Hadoux J, Chougnet CN, Leboulleux S, et al. Are G3 ENETS neuroendocrine neoplasms heterogeneous? Endocr Relat Cancer (2013) 20:649-57. doi: 10.1530/ERC-13-0027

8. Basturk O, Yang Z, Tang LH, Hruban RH, Adsay V, McCall CM, et al. The high-grade (WHO G3) pancreatic neuroendocrine tumor category is morphologically and biologically heterogenous and includes both well differentiated and poorly differentiated neoplasms. Am J Surg Pathol (2015) 39:683-90. doi: 10.1097/PAS.0000000000000408

9. Heetfeld M, Chougnet CN, Olsen IH, Rinke A, Borbath I, Crespo G, et al. Characteristics and treatment of patients with G3 gastroenteropancreatic neuroendocrine neoplasms. Endocr Relat Cancer (2015) 22:657-64. doi: 10.1530/ERC-15-0119

10. Sorbye H, Welin S, Langer SW, Vestermark LW, Holt N, Osterlund P, et al. Predictive and prognostic factors for treatment and survival in 305 patients with advanced gastrointestinal neuroendocrine carcinoma (WHO G3): the NORDIC NEC study. Ann Oncol (2013) 24:152-60. doi: 10.1093/annonc/mds276

11. Zhang J, Francois R, Iyer R, Seshadri M, Zajac-Kaye M, Hochwald SN. Current understanding of the molecular biology of pancreatic neuroendocrine tumors. J Natl Cancer Inst (2013) 105:1005-17. doi: 10.1093/jnci/djt135

12. Strosberg JR, Cheema A, Weber JM, Ghayouri M, Han G, Hodul PJ, et al. Relapse-free survival in patients with nonmetastatic, surgically resected pancreatic neuroendocrine tumors: an analysis of the AJCC and ENETS staging classifications. Ann Surg (2012) 256:321-5. doi: 10.1097/ SLA.0b013e31824e6108

13. Franko J, Feng W, Yip L, Genovese E, Moser AJ. Non-functional neuroendocrine carcinoma of the pancreas: incidence, tumor biology, and outcomes in 2,158 patients. J Gastrointest Surg (2010) 14:541-8. doi: $10.1007 / \mathrm{s} 11605-009-1115-0$

\section{FUNDING}

Funding support for this review was provided by the Intramural Research Program of the National Institutes of Health: NCI (SS and PC) and NIDDK (SA). ZIA DK075035-12 for SA.

\section{ACKNOWLEDGMENTS}

The authors would like to acknowledge the Medical Arts Department of the National Cancer Institute for their assistance in drafting graphics presented herein.

14. Jiao Y, Shi C, Edil BH, de Wilde RF, Klimstra DS, Maitra A, et al. DAXX/ ATRX, MEN1, and mTOR pathway genes are frequently altered in pancreatic neuroendocrine tumors. Science (2011) 331:1199-203. doi: 10.1126/science.1200609

15. Halfdanarson TR, Rabe KG, Rubin J, Petersen GM. Pancreatic neuroendocrine tumors (PNETs): incidence, prognosis and recent trend toward improved survival. Ann Oncol (2008) 19:1727-33. doi: 10.1093/annonc/mdn351

16. Guilmette JM, Nose V. Neoplasms of the Neuroendocrine Pancreas: An Update in the Classification, Definition, and Molecular Genetic Advances. Adv Anat Pathol (2019) 26:13-30. doi: 10.1097/PAP.0000000000000201

17. Chiloiro S, Lanza F, Bianchi A, Schinzari G, Brizi MG, Giampietro A, et al. Pancreatic neuroendocrine tumors in MEN1 disease: a mono-centric longitudinal and prognostic study. Endocrine (2018) 60:362-7. doi: 10.1007/s12020-017-1327-0

18. Frederiksen A, Rossing M, Hermann P, Ejersted C, Thakker RV, Frost M. Clinical Features of Multiple Endocrine Neoplasia Type 4: Novel Pathogenic Variant and Review of Published Cases. J Clin Endocrinol Metab (2019) 104:3637-46. doi: 10.1210/jc.2019-00082

19. Thakker RV, Newey PJ, Walls GV, Bilezikian J, Dralle H, Ebeling PR, et al Clinical practice guidelines for multiple endocrine neoplasia type 1 (MEN1). J Clin Endocrinol Metab (2012) 97:2990-3011. doi: 10.1210/jc.2012-1230

20. Keutgen XM, Nilubol N, Glanville J, Sadowski SM, Liewehr DJ, Venzon DJ, et al. Resection of primary tumor site is associated with prolonged survival in metastatic nonfunctioning pancreatic neuroendocrine tumors. Surgery (2016) 159:311-8. doi: 10.1016/j.surg.2015.05.042

21. Bar-Moshe Y, Mazeh H, Grozinsky-Glasberg S. Non-functioning pancreatic neuroendocrine tumors: Surgery or observation? World J Gastrointest Endosc (2017) 9:153-61. doi: 10.4253/wjge.v9.i4.153

22. Cloyd JM, Poultsides GA. Non-functional neuroendocrine tumors of the pancreas: Advances in diagnosis and management. World J Gastroenterol (2015) 21:9512-25. doi: 10.3748/wjg.v21.i32.9512

23. Yao JC, Shah MH, Ito T, Bohas CL, Wolin EM, Van Cutsem E, et al. Rad001 in Advanced Neuroendocrine Tumors, Everolimus for advanced pancreatic neuroendocrine tumors. N Engl J Med (2011) 364:514-23. doi: 10.1056/ NEJMoa1009290

24. Rinke A, Muller HH, Schade-Brittinger C, Klose KJ, Barth P, Wied M, et al. Placebo-controlled, double-blind, prospective, randomized study on the effect of octreotide LAR in the control of tumor growth in patients with metastatic neuroendocrine midgut tumors: a report from the PROMID Study Group. J Clin Oncol (2009) 27:4656-63. doi: 10.1200/JCO. 2009.22.8510

25. Caplin ME, Pavel M, Cwikla JB, Phan AT, Raderer M, Sedlackova E, et al. Lanreotide in metastatic enteropancreatic neuroendocrine tumors. $N$ Engl J Med (2014) 371:224-33. doi: 10.1056/NEJMoa1316158

26. Mafficini A, Scarpa A. Genomic landscape of pancreatic neuroendocrine tumours: the International Cancer Genome Consortium. J Endocrinol (2018) 236:R161-7. doi: 10.1530/JOE-17-0560

27. Wang $\mathrm{H}$, Bender $\mathrm{A}$, Wang $\mathrm{P}$, Karakose $\mathrm{E}$, Inabnet WB, Libutti SK, et al. Insights into beta cell regeneration for diabetes via integration of molecular landscapes in human insulinomas. Nat Commun (2017) 8:767. doi: 10.1038/ s41467-017-00992-9 
28. Cao Y, Gao Z, Li L, Jiang X, Shan A, Cai J, et al. Whole exome sequencing of insulinoma reveals recurrent T372R mutations in YY1. Nat Commun (2013) 4:2810. doi: $10.1038 /$ ncomms 3810

29. Cromer MK, Choi M, Nelson-Williams C, Fonseca AL, Kunstman JW, Korah RM, et al. Neomorphic effects of recurrent somatic mutations in Yin Yang 1 in insulin-producing adenomas. Proc Natl Acad Sci U S A (2015) 112:4062-7. doi: 10.1073/pnas.1503696112

30. Parekh VI, Modali SD, Welch J, Simonds WF, Weinstein LS, Kebebew E, et al. Frequency and consequence of the recurrent YY1 p.T372R mutation in sporadic insulinomas. Endocr Relat Cancer (2018) 25:L31-5. doi: 10.1530/ ERC-17-0311

31. Corbo V, Dalai I, Scardoni M, Barbi S, Beghelli S, Bersani S, et al. MEN1 in pancreatic endocrine tumors: analysis of gene and protein status in 169 sporadic neoplasms reveals alterations in the vast majority of cases. Endocr Relat Cancer (2010) 17:771-83. doi: 10.1677/ERC-10-0028

32. Hough DM, Stephens DH, Johnson CD, Binkovitz LA. Pancreatic lesions in von Hippel-Lindau disease: prevalence, clinical significance, and CT findings. AJR Am J Roentgenol (1994) 162:1091-4. doi: 10.2214/ ajr.162.5.8165988

33. Heaphy CM, de Wilde RF, Jiao Y, Klein AP, Edil BH, Shi C, et al. Altered telomeres in tumors with ATRX and DAXX mutations. Science (2011) 333:425. doi: 10.1126/science. 1207313

34. Cejas P, Drier Y, Dreijerink KMA, Brosens LAA, Deshpande V, Epstein CB, et al. Enhancer signatures stratify and predict outcomes of non-functional pancreatic neuroendocrine tumors. Nat Med (2019) 25:1260-5. doi: 10.1038/ s41591-019-0493-4

35. Scarpa A, Chang DK, Nones K, Corbo V, Patch AM, Bailey P, et al. Wholegenome landscape of pancreatic neuroendocrine tumours. Nature (2017) 543:65-71. doi: 10.1038/nature21063/nature21063

36. Agarwal SK, Lee Burns A, Sukhodolets KE, Kennedy PA, Obungu VH, Hickman AB, et al. Molecular pathology of the MEN1 gene. Ann N Y Acad Sci (2004) 1014:189-98. doi: 10.1196/annals.1294.020

37. Sadowski SM, Pieterman CRC, Perrier ND, Triponez F, Valk GD. Prognostic factors for the outcome of nonfunctioning pancreatic neuroendocrine tumors in MEN1: a systematic review of literature. Endocr Relat Cancer (2020) 27(6):R145-61. doi: 10.1530/ERC-19-0372

38. Wang EH, Ebrahimi SA, Wu AY, Kashefi C, Passaro E Jr., Sawicki MP. Mutation of the MENIN gene in sporadic pancreatic endocrine tumors. Cancer Res (1998) 58:4417-20.

39. Corbo V, Beghelli S, Bersani S, Antonello D, Talamini G, Brunelli M, et al. Pancreatic endocrine tumours: mutational and immunohistochemical survey of protein kinases reveals alterations in targetable kinases in cancer cell lines and rare primaries. Ann Oncol (2012) 23:127-34. doi: 10.1093/ annonc/mdr048

40. Thakker RV. Multiple endocrine neoplasia type 1 (MEN1) and type 4 (MEN4). Mol Cell Endocrinol (2014) 386:2-15. doi: 10.1016/j.mce.2013.08.002

41. Hammel PR, Vilgrain V, Terris B, Penfornis A, Sauvanet A, Correas JM, et al. Pancreatic involvement in von Hippel-Lindau disease. The Groupe Francophone d'Etude de la Maladie de von Hippel-Lindau. Gastroenterology (2000) 119:1087-95. doi: 10.1053/gast.2000.18143

42. Blansfield JA, Choyke L, Morita SY, Choyke PL, Pingpank JF, Alexander HR, et al. Clinical, genetic and radiographic analysis of 108 patients with von Hippel-Lindau disease (VHL) manifested by pancreatic neuroendocrine neoplasms (PNETs). Surgery (2007) 142:814-8; discussion 818 e1-2. doi: 10.1016/j.surg.2007.09.012

43. Libutti SK, Choyke PL, Bartlett DL, Vargas H, Walther M, Lubensky I, et al. Pancreatic neuroendocrine tumors associated with von Hippel Lindau disease: diagnostic and management recommendations. Surgery (1998) 124:1153-9. doi: 10.1067/msy.1998.91823

44. Libutti SK, Choyke PL, Alexander HR, Glenn G, Bartlett DL, Zbar B, et al. Clinical and genetic analysis of patients with pancreatic neuroendocrine tumors associated with von Hippel-Lindau disease. Surgery (2000) 128:1022-7; discussion 1027-8. doi: 10.1067/msy.2000.110239

45. de Mestier L, Gaujoux S, Cros J, Hentic O, Vullierme MP, Couvelard A, et al. Long-term Prognosis of Resected Pancreatic Neuroendocrine Tumors in von Hippel-Lindau Disease Is Favorable and Not Influenced by Small Tumors Left in Place. Ann Surg (2015) 262:384-8. doi: 10.1097/SLA. 0000000000000856
46. Speisky D, Duces A, Bieche I, Rebours V, Hammel P, Sauvanet A, et al. Molecular profiling of pancreatic neuroendocrine tumors in sporadic and Von Hippel-Lindau patients. Clin Cancer Res (2012) 18:2838-49. doi: 10.1158/1078-0432.CCR-11-2759

47. Pugh CW, Ratcliffe PJ. Regulation of angiogenesis by hypoxia: role of the HIF system. Nat Med (2003) 9:677-84. doi: 10.1038/nm0603-677

48. Terris B, Scoazec JY, Rubbia L, Bregeaud L, Pepper MS, Ruszniewski P, et al. Expression of vascular endothelial growth factor in digestive neuroendocrine tumours. Histopathology (1998) 32:133-8. doi: 10.1046/j.13652559.1998.00321.x

49. Couvelard A, O’Toole D, Turley H, Leek R, Sauvanet A, Degott C, et al. Microvascular density and hypoxia-inducible factor pathway in pancreatic endocrine tumours: negative correlation of microvascular density and VEGF expression with tumour progression. Br J Cancer (2005) 92:94-101. doi: 10.1038/sj.bjc. 6602245

50. Marion-Audibert AM, Barel C, Gouysse G, Dumortier J, Pilleul F, Pourreyron C, et al. Low microvessel density is an unfavorable histoprognostic factor in pancreatic endocrine tumors. Gastroenterology (2003) 125:1094-104. doi: 10.1016/S0016-5085(03)01198-3

51. Kulke MH, Lenz HJ, Meropol NJ, Posey J, Ryan DP, Picus J, et al. Activity of sunitinib in patients with advanced neuroendocrine tumors. J Clin Oncol (2008) 26:3403-10. doi: 10.1200/JCO.2007.15.9020

52. Hobday TJ, Qin R, Reidy-Lagunes D, Moore MJ, Strosberg J, Kaubisch A, et al. Multicenter Phase II Trial of Temsirolimus and Bevacizumab in Pancreatic Neuroendocrine Tumors. J Clin Oncol (2015) 33:1551-6. doi: 10.1200/JCO.2014.56.2082

53. Xu J, Li J, Bai C, Xu N, Zhou Z, Li Z, et al. Surufatinib in Advanced WellDifferentiated Neuroendocrine Tumors: A Multicenter, Single-Arm, OpenLabel, Phase Ib/II Trial. Clin Cancer Res (2019) 25:3486-94. doi: 10.1158/ 1078-0432.CCR-18-2994

54. Elsaesser SJ, Allis CD. HIRA and Daxx constitute two independent histone H3.3-containing predeposition complexes. Cold Spring Harb Symp Quant Biol (2010) 75:27-34. doi: 10.1101/sqb.2010.75.008

55. Goldberg AD, Banaszynski LA, Noh KM, Lewis PW, Elsaesser SJ, Stadler S, et al. Distinct factors control histone variant H3.3 localization at specific genomic regions. Cell (2010) 140:678-91. doi: 10.1016/j.cell.2010.01.003

56. Lewis PW, Elsaesser SJ, Noh KM, Stadler SC, Allis CD. Daxx is an H3.3specific histone chaperone and cooperates with ATRX in replicationindependent chromatin assembly at telomeres. Proc Natl Acad Sci U S A (2010) 107:14075-80. doi: 10.1073/pnas.1008850107

57. Heaphy CM, Subhawong AP, Hong SM, Goggins MG, Montgomery EA, Gabrielson E, et al. Prevalence of the alternative lengthening of telomeres telomere maintenance mechanism in human cancer subtypes. Am J Pathol (2011) 179:1608-15. doi: 10.1016/j.ajpath.2011.06.018

58. Yachida S, Vakiani E, White CM, Zhong Y, Saunders T, Morgan R, et al. Small cell and large cell neuroendocrine carcinomas of the pancreas are genetically similar and distinct from well-differentiated pancreatic neuroendocrine tumors. Am J Surg Pathol (2012) 36:173-84. doi: 10.1097/ PAS.0b013e3182417d36

59. Marinoni I, Kurrer AS, Vassella E, Dettmer M, Rudolph T, Banz V, et al. Loss of DAXX and ATRX are associated with chromosome instability and reduced survival of patients with pancreatic neuroendocrine tumors. Gastroenterology (2014) 146:453-60.e5. doi: 10.1053/j.gastro.2013.10.020

60. Park JK, Paik WH, Lee K, Ryu JK, Lee SH, Kim YT. DAXX/ATRX and MEN1 genes are strong prognostic markers in pancreatic neuroendocrine tumors. Oncotarget (2017) 8:49796-806. doi: 10.18632/oncotarget.17964

61. de Wilde RF, Heaphy CM, Maitra A, Meeker AK, Edil BH, Wolfgang CL, et al. Loss of ATRX or DAXX expression and concomitant acquisition of the alternative lengthening of telomeres phenotype are late events in a small subset of MEN-1 syndrome pancreatic neuroendocrine tumors. Mod Pathol (2012) 25:1033-9. doi: 10.1038/modpathol.2012.53

62. Kim JY, Brosnan-Cashman JA, An S, Kim SJ, Song KB, Kim MS, et al. Alternative Lengthening of Telomeres in Primary Pancreatic Neuroendocrine Tumors Is Associated with Aggressive Clinical Behavior and Poor Survival. Clin Cancer Res (2017) 23:1598-606. doi: 10.1158/10780432.CCR-16-1147

63. Singhi AD, Liu TC, Roncaioli JL, Cao D, Zeh HJ, Zureikat AH, et al. Alternative Lengthening of Telomeres and Loss of DAXX/ATRX Expression 
Predicts Metastatic Disease and Poor Survival in Patients with Pancreatic Neuroendocrine Tumors. Clin Cancer Res (2017) 23:600-9. doi: 10.1158/ 1078-0432.CCR-16-1113

64. Missiaglia E, Dalai I, Barbi S, Beghelli S, Falconi M, della Peruta M, et al. Pancreatic endocrine tumors: expression profiling evidences a role for AKTmTOR pathway. J Clin Oncol (2010) 28:245-55. doi: 10.1200/JCO. 2008.21.5988

65. Gebauer N, Schmidt-Werthern C, Bernard V, Feller AC, Keck T, Begum N, et al. Genomic landscape of pancreatic neuroendocrine tumors. World J Gastroenterol (2014) 20:17498-506. doi: 10.3748/wjg.v20.i46.17498

66. Friedman RC, Farh KK, Burge CB, Bartel DP. Most mammalian mRNAs are conserved targets of microRNAs. Genome Res (2009) 19:92-105. doi: $10.1101 /$ gr.082701.108

67. Roldo C, Missiaglia E, Hagan JP, Falconi M, Capelli P, Bersani S, et al. MicroRNA expression abnormalities in pancreatic endocrine and acinar tumors are associated with distinctive pathologic features and clinical behavior. J Clin Oncol (2006) 24:4677-84. doi: 10.1200/JCO.2005.05.5194

68. Sadanandam A, Wullschleger S, Lyssiotis CA, Grotzinger C, Barbi S, Bersani S, et al. A Cross-Species Analysis in Pancreatic Neuroendocrine Tumors Reveals Molecular Subtypes with Distinctive Clinical, Metastatic, Developmental, and Metabolic Characteristics. Cancer Discov (2015) 5:1296-313. doi: 10.1158/2159-8290.CD-15-0068

69. Lee YS, Kim H, Kim HW, Lee JC, Paik KH, Kang J, et al. High Expression of MicroRNA-196a Indicates Poor Prognosis in Resected Pancreatic Neuroendocrine Tumor. Medicine (Baltimore) (2015) 94:e2224. doi: 10.1097/MD.0000000000002224

70. Malczewska A, Kidd M, Matar S, Kos-Kudla B, Modlin IM. A Comprehensive Assessment of the Role of miRNAs as Biomarkers in Gastroenteropancreatic Neuroendocrine Tumors. Neuroendocrinology (2018) 107:73-90. doi: 10.1159/000487326

71. Tirosh A, Mukherjee S, Lack J, Gara SK, Wang S, Quezado MM, et al. Distinct genome-wide methylation patterns in sporadic and hereditary nonfunctioning pancreatic neuroendocrine tumors. Cancer (2019) 125:1247-57. doi: 10.1002/cncr.31930

72. Conemans EB, Lodewijk L, Moelans CB, Offerhaus GJA, Pieterman CRC, Morsink FH, et al. DNA methylation profiling in MEN1-related pancreatic neuroendocrine tumors reveals a potential epigenetic target for treatment. Eur J Endocrinol (2018) 179:153-60. doi: 10.1530/EJE-18-0195

73. Mattox AK, Bettegowda C, Zhou S, Papadopoulos N, Kinzler KW, Vogelstein B. Applications of liquid biopsies for cancer. Sci Transl Med (2019) 11(507):eaay1984. doi: 10.1126/scitranslmed.aay1984

74. Malczewska A, Kos-Kudla B, Kidd M, Drozdov I, Bodei L, Matar S, et al. The clinical applications of a multigene liquid biopsy (NETest) in neuroendocrine tumors. Adv Med Sci (2020) 65:18-29. doi: 10.1016/j.advms. 2019.10.002

75. Genc CG, Jilesen APJ, Nieveen van Dijkum EJM, Klumpen HJ, van Eijck $\mathrm{CHJ}$, Drozdov I, et al. Measurement of circulating transcript levels (NETest) to detect disease recurrence and improve follow-up after curative surgical resection of well-differentiated pancreatic neuroendocrine tumors. J Surg Oncol (2018) 118:37-48. doi: 10.1002/jso.25129

76. Oberg K, Califano A, Strosberg JR, Ma S, Pape U, Bodei L, et al. A metaanalysis of the accuracy of a neuroendocrine tumor mRNA genomic biomarker (NETest) in blood. Ann Oncol (2020) 31:202-12. doi: 10.1016/ j.annonc.2019.11.003

77. Hijioka S, Hosoda W, Matsuo K, Ueno M, Furukawa M, Yoshitomi H, et al. $\mathrm{Rb}$ Loss and KRAS Mutation Are Predictors of the Response to PlatinumBased Chemotherapy in Pancreatic Neuroendocrine Neoplasm with Grade 3: A Japanese Multicenter Pancreatic NEN-G3 Study. Clin Cancer Res (2017) 23:4625-32. doi: 10.1158/1078-0432.CCR-16-3135

78. Garcia-Carbonero R, Sorbye H, Baudin E, Raymond E, Wiedenmann B, Niederle B, et al. ENETS Consensus Guidelines for High-Grade Gastroenteropancreatic Neuroendocrine Tumors and Neuroendocrine Carcinomas. Neuroendocrinology (2016) 103:186-94. doi: 10.1159/ 000443172

79. Shah MH, Goldner WS, Halfdanarson TR, Bergsland E, Berlin JD, Halperin D, et al. NCCN Guidelines Insights: Neuroendocrine and Adrenal Tumors, Version 2.2018. J Natl Compr Canc Netw (2018) 16:693-702. doi: 10.6004/ jnccn.2018.0056
80. Panzuto F, Boninsegna L, Fazio N, Campana D, Pia Brizzi M, Capurso G, et al. Metastatic and locally advanced pancreatic endocrine carcinomas: analysis of factors associated with disease progression. J Clin Oncol (2011) 29:2372-7. doi: 10.1200/JCO.2010.33.0688

81. Raymond E, Dahan L, Raoul JL, Bang YJ, Borbath I, Lombard-Bohas C, et al. Sunitinib malate for the treatment of pancreatic neuroendocrine tumors. N Engl J Med (2011) 364:501-13. doi: 10.1056/NEJMoa1003825

82. Raymond E, Niccoli P, Raoul J, Bang Y, Borbath I, Lombard-Bohas C, et al. Updated overall survival (OS) and progression-free survival (PFS) by blinded independent central review (BICR) of sunitinib (SU) versus placebo (PBO) for patients (Pts) with advanced unresectable pancreatic neuroendocrine tumors (NET). J Clin Oncol (2011) 29:4008-8. doi: 10.1200/ jco.2011.29.15_suppl.4008

83. Strosberg J, El-Haddad G, Wolin E, Hendifar A, Yao J, Chasen B, et al. Phase 3 Trial of (177)Lu-Dotatate for Midgut Neuroendocrine Tumors. N Engl J Med (2017) 376:125-35. doi: 10.1056/NEJMoa1607427

84. Yao JC, Pavel M, Lombard-Bohas C, Van Cutsem E, Voi M, Brandt U, et al. Everolimus for the Treatment of Advanced Pancreatic Neuroendocrine Tumors: Overall Survival and Circulating Biomarkers From the Randomized, Phase III RADIANT-3 Study. J Clin Oncol (2016) 34:390613. doi: $10.1200 /$ JCO.2016.68.0702

85. Sadowski SM, Neychev V, Millo C, Shih J, Nilubol N, Herscovitch P, et al. Prospective Study of 68Ga-DOTATATE Positron Emission Tomography/ Computed Tomography for Detecting Gastro-Entero-Pancreatic Neuroendocrine Tumors and Unknown Primary Sites. J Clin Oncol (2016) 34:588-96. doi: 10.1200/JCO.2015.64.0987

86. Tirosh A, Kebebew E. The utility of (68)Ga-DOTATATE positron-emission tomography/computed tomography in the diagnosis, management, followup and prognosis of neuroendocrine tumors. Future Oncol (2018) 14:11122. doi: $10.2217 /$ fon-2017-0393

87. Papotti M, Bongiovanni M, Volante M, Allia E, Landolfi S, Helboe L, et al. Expression of somatostatin receptor types 1-5 in 81 cases of gastrointestinal and pancreatic endocrine tumors. A correlative immunohistochemical and reverse-transcriptase polymerase chain reaction analysis. Virchows Arch (2002) 440:461-75. doi: 10.1007/s00428-002-0609-x

88. Laskaratos FM, Walker M, Naik K, Maragkoudakis E, Oikonomopoulos N, Grant L, et al. Predictive factors of antiproliferative activity of octreotide LAR as first-line therapy for advanced neuroendocrine tumours. Br J Cancer (2016) 115:1321-7. doi: 10.1038/bjc.2016.349

89. Zhang J, Jia Z, Li Q, Wang L, Rashid A, Zhu Z, et al. Elevated expression of vascular endothelial growth factor correlates with increased angiogenesis and decreased progression-free survival among patients with low-grade neuroendocrine tumors. Cancer (2007) 109:1478-86. doi: 10.1002/cncr.22554

90. Sennino B, Ishiguro-Oonuma T, Wei Y, Naylor RM, Williamson CW, Bhagwandin V, et al. Suppression of tumor invasion and metastasis by concurrent inhibition of c-Met and VEGF signaling in pancreatic neuroendocrine tumors. Cancer Discov (2012) 2:270-87. doi: 10.1158/ 2159-8290.CD-11-0240

91. Lee ME, Tepede AA, Mandl A, Weinstein LS, Del Rivero J, Agarwal SK, et al. c-MET Inhibition: Novel Treatment for Sporadic and MEN1-associated GEP NET. J Mol Endocrinol (2020) 65(2):R1-R17. doi: 10.1530/JME-200020

92. Martins D, Spada F, Lambrescu I, Rubino M, Cella C, Gibelli B, et al. Predictive Markers of Response to Everolimus and Sunitinib in Neuroendocrine Tumors. Target Oncol (2017) 12:611-22. doi: 10.1007/ s11523-017-0506-5

93. Yao JC, Pavel M, Phan AT, Kulke MH, Hoosen S, St Peter J, et al. Chromogranin A and neuron-specific enolase as prognostic markers in patients with advanced pNET treated with everolimus. J Clin Endocrinol Metab (2011) 96:3741-9. doi: 10.1210/jc.2011-0666

94. Modlin IM, Gustafsson BI, Moss SF, Pavel M, Tsolakis AV, Kidd M. Chromogranin A-biological function and clinical utility in neuro endocrine tumor disease. Ann Surg Oncol (2010) 17:2427-43. doi: 10.1245/s10434-010-1006-3

95. Passacantilli I, Capurso G, Archibugi L, Calabretta S, Caldarola S, Loreni F, et al. Combined therapy with RAD001 e BEZ235 overcomes resistance of PET immortalized cell lines to mTOR inhibition. Oncotarget (2014) 5:538191. doi: 10.18632/oncotarget.2111 
96. Zitzmann K, Ruden J, Brand S, Goke B, Lichtl J, Spottl G, et al. Compensatory activation of Akt in response to mTOR and Raf inhibitors - a rationale for dual-targeted therapy approaches in neuroendocrine tumor disease. Cancer Lett (2010) 295:100-9. doi: 10.1016/j.canlet.2010.02.018

97. Markman B, Dienstmann R, Tabernero J. Targeting the PI3K/Akt/mTOR pathway-beyond rapalogs. Oncotarget (2010) 1:530-43. doi: 10.18632/ oncotarget.188

98. Antonuzzo L, Del Re M, Barucca V, Spada F, Meoni G, Restante G, et al. Critical focus on mechanisms of resistance and toxicity of $\mathrm{m}$-TOR inhibitors in pancreatic neuroendocrine tumors. Cancer Treat Rev (2017) 57:28-35. doi: 10.1016/j.ctrv.2017.05.001

99. Di Nicolantonio F, Arena S, Tabernero J, Grosso S, Molinari F, Macarulla T, et al. Deregulation of the PI3K and KRAS signaling pathways in human cancer cells determines their response to everolimus. J Clin Invest (2010) 120:2858-66. doi: 10.1172/JCI37539

100. Zatelli MC, Fanciulli G, Malandrino P, Ramundo V, Faggiano A, Colao A, et al. Predictive factors of response to $\mathrm{mTOR}$ inhibitors in neuroendocrine tumours. Endocr Relat Cancer (2016) 23:R173-83. doi: 10.1530/ERC-150413

101. Duran I, Kortmansky J, Singh D, Hirte H, Kocha W, Goss G, et al. A phase II clinical and pharmacodynamic study of temsirolimus in advanced neuroendocrine carcinomas. Br J Cancer (2006) 95:1148-54. doi: 10.1038/ sj.bjc. 6603419

102. da Silva A, Bowden M, Zhang S, Masugi Y, Thorner AR, Herbert ZT, et al. Characterization of the Neuroendocrine Tumor Immune Microenvironment. Pancreas (2018) 47:1123-9. doi: 10.1097/MPA.00000 00000001150

103. Mehnert JM, Bergsland E, O’Neil BH, Santoro A, Schellens JHM, Cohen RB, et al. Pembrolizumab for the treatment of programmed death-ligand 1positive advanced carcinoid or pancreatic neuroendocrine tumors: Results from the KEYNOTE-028 study. Cancer (2020) 126(13):3021-30. doi: 10.1002/cncr.32883

104. Moertel CG, Lefkopoulo M, Lipsitz S, Hahn RG, Klaassen D. Streptozocindoxorubicin, streptozocin-fluorouracil or chlorozotocin in the treatment of advanced islet-cell carcinoma. N Engl J Med (1992) 326:519-23. doi: 10.1056/ NEJM199202203260804

105. Chan JA, Kulke MH. Medical Management of Pancreatic Neuroendocrine Tumors: Current and Future Therapy. Surg Oncol Clin N Am (2016) 25:42337. doi: 10.1016/j.soc.2015.11.009

106. Strosberg JR, Fine RL, Choi J, Nasir A, Coppola D, Chen DT, et al. First-line chemotherapy with capecitabine and temozolomide in patients with metastatic pancreatic endocrine carcinomas. Cancer (2011) 117:268-75. doi: $10.1002 / \mathrm{cncr} .25425$

107. Kulke MH, Stuart K, Enzinger PC, Ryan DP, Clark JW, Muzikansky A, et al. Phase II study of temozolomide and thalidomide in patients with metastatic neuroendocrine tumors. J Clin Oncol (2006) 24:401-6. doi: 10.1200/ JCO.2005.03.6046

108. Chan JA, Stuart K, Earle CC, Clark JW, Bhargava P, Miksad R, et al. Prospective study of bevacizumab plus temozolomide in patients with advanced neuroendocrine tumors. J Clin Oncol (2012) 30:2963-8. doi: 10.1200/JCO.2011.40.3147

109. Welin S, Sorbye H, Sebjornsen S, Knappskog S, Busch C, Oberg K. Clinical effect of temozolomide-based chemotherapy in poorly differentiated endocrine carcinoma after progression on first-line chemotherapy. Cancer (2011) 117:4617-22. doi: 10.1002/cncr.26124

110. Kulke MH, Hornick JL, Frauenhoffer C, Hooshmand S, Ryan DP, Enzinger PC, et al. O6-methylguanine DNA methyltransferase deficiency and response to temozolomide-based therapy in patients with neuroendocrine tumors. Clin Cancer Res (2009) 15:338-45. doi: 10.1158/1078-0432.CCR-081476

111. Cros J, Hentic O, Rebours V, Zappa M, Gille N, Theou-Anton N, et al. MGMT expression predicts response to temozolomide in pancreatic neuroendocrine tumors. Endocr Relat Cancer (2016) 23:625. doi: 10.1530/ ERC-16-0117

112. Scarpa A. The landscape of molecular alterations in pancreatic and small intestinal neuroendocrine tumours. Ann Endocrinol (Paris) (2019) 80:153-8. doi: $10.1016 /$ j.ando.2019.04.010

113. Scott AT, Weitz M, Breheny PJ, Ear PH, Darbro B, Brown BJ, et al. Gene Expression Signatures Identify Novel Therapeutics for Metastatic Pancreatic Neuroendocrine Tumors. Clin Cancer Res (2020) 26(8):2011-21. doi: 10.1158/1078-0432.CCR-19-2884

114. Alvarez MJ, Subramaniam PS, Tang LH, Grunn A, Aburi M, Rieckhof G, et al. A precision oncology approach to the pharmacological targeting of mechanistic dependencies in neuroendocrine tumors. Nat Genet (2018) 50:979-89. doi: 10.1038/s41588-018-0138-4

115. Hofving T, Arvidsson Y, Almobarak B, Inge L, Pfragner R, Persson M, et al. The neuroendocrine phenotype, genomic profile and therapeutic sensitivity of GEPNET cell lines. Endocr Relat Cancer (2018) 25:367-80. doi: 10.1530/ ERC-17-0445

Conflict of Interest: The authors declare that the research was conducted in the absence of any commercial or financial relationships that could be construed as a potential conflict of interest.

Copyright (c) 2021 Chatani, Agarwal and Sadowski. This is an open-access article distributed under the terms of the Creative Commons Attribution License (CC BY). The use, distribution or reproduction in other forums is permitted, provided the original author(s) and the copyright owner(s) are credited and that the original publication in this journal is cited, in accordance with accepted academic practice. No use, distribution or reproduction is permitted which does not comply with these terms. 